\title{
Social consequences of the globalization of the media and communication sector: some strategic considerations
}

Working Paper No. 36

Seán Ó. Siochrú

Policy Integration Department

Word Commission on the Social Dimension of Globalization

International Labour Office

Geneva

May 2004 
Copyright $\mathbb{C}$ International Labour Organization 2004

Publications of the International Labour Office enjoy copyright under Protocol 2 of the Universal Copyright Convention. Nevertheless, short excerpts from them may be reproduced without authorization, on condition that the source is indicated. For rights of reproduction or translation, application should be made to the Publications Bureau (Rights and Permissions), International Labour Office, CH-1211 Geneva 22, Switzerland. The International Labour Office welcomes such applications.

Libraries, institutions and other users registered in the United Kingdom with the Copyright Licensing Agency, 90 Tottenham Court Road, London W1T 4LP [Fax: (+44) (0)20 7631 5500; email: cla@cla.co.uk], in the United States with the Copyright Clearance Center, 222 Rosewood Drive, Danvers, MA 01923 [Fax: (+1) (978) 750 4470; email: info@copyright.com] or in other countries with associated Reproduction Rights Organizations, may make photocopies in accordance with the licences issued to them for this purpose.

ISBN 92-2-115794-6 (printed version)

ISBN 92-2-115795-4 (web version)

First published 2004

The designations employed in ILO publications, which are in conformity with United Nations practice, and the presentation of material therein do not imply the expression of any opinion whatsoever on the part of the International Labour Office concerning the legal status of any country, area or territory or of its authorities, or concerning the delimitation of its frontiers.

The responsibility for opinions expressed in signed articles, studies and other contributions rests solely with their authors, and publication does not constitute an endorsement by the International Labour Office of the opinions expressed in them.

Reference to names of firms and commercial products and processes does not imply their endorsement by the International Labour Office, and any failure to mention a particular firm, commercial product or process is not a sign of disapproval.

ILO publications can be obtained through major booksellers or ILO local offices in many countries, or direct from ILO Publications, International Labour Office, $\mathrm{CH}-1211$ Geneva 22, Switzerland. Catalogues or lists of new publications are available free of charge from the above address, or by email: pubvente@ilo.org

Visit our website: www.ilo.org/publns 
Social consequences of the globalization of

the media and communication sector:

Some strategic considerations

\section{Contents}

Foreword iii

Preface. $\mathrm{V}$

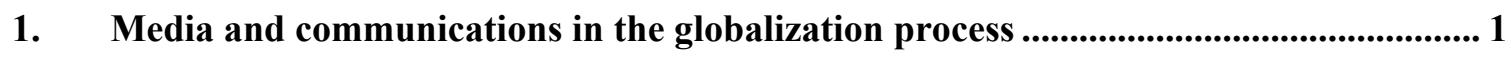

2. Are media "products" just like other commodities?............................................... 3

3. Global governance institutions and actors in media and communications.................... 4

Media governance institutions ............................................................................ 4

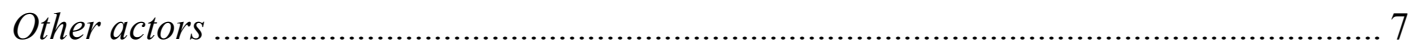

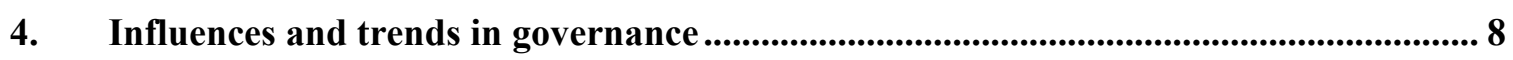

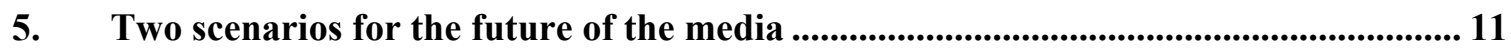

Scenario 1: A dominant trade and liberalization paradigm....................................... 12

Scenario 2: Multilateral cooperation reborn .......................................................... 14

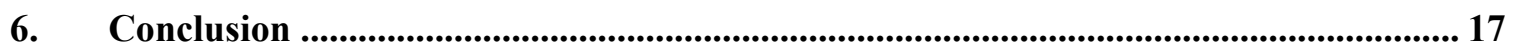




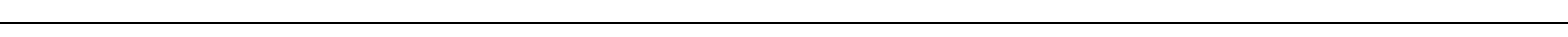




\title{
Foreword
}

In February 2002, the ILO established an independent World Commission on the Social Dimension of Globalization, co-chaired by President Tarja Halonen of Finland and President Benjamin Mkapa of Tanzania and comprising 26 eminent commissioners from a wide range of walks of life and different parts of the world, each serving in their individual capacity. Its broad goals were: to identify policies for globalization that reduce poverty, foster growth and development in open economies, and widen opportunities for decent work; to explore ways to make globalization inclusive, so that the process can be seen to be fair for all, both between and within countries; to promote a more focused international dialogue on the social dimension of globalization; to build consensus among key actors and stakeholders on appropriate policy responses; and to assist the international community forge greater policy coherence in order to advance both economic and social goals in the global economy.

The report of the World Commission, A fair globalization: Creating opportunities for all, was released on 24 February 2004. It is available on the Commission's website www.ilo.org/public/english/wcsdg/index.htm.

A secretariat was established by the ILO to support the Commission. Among other tasks, it compiled information and commissioned papers on different aspects of the social dimension of globalization. The aim was to provide the Commission with documentation and data on a wide range of options and opinions concerning subjects within its mandate, without committing the Commission or individual Commissioners to any particular position on the issues or policies concerned.

Material from this background work is being made available as working papers, as national and regional reports on meetings and dialogues, and in other forms. Responsibility for the content of these papers and publications rests fully with their authors and their publication does not constitute an endorsement by the World Commission or the ILO of the opinions expressed in them.

\author{
Gerry Rodgers \\ Director \\ Policy Integration Department
}




\title{
Preface
}

The Technical Secretariat to support the World Commission on the Social Dimension of Globalization first prepared a synthesis of ILO activities on the Social Dimension of Globalization (published as Working Paper No. 1 in this series). Documentation on the work and outcomes of other major commissions, an ideas bank, a database and knowledge networks of experts and social actors were subsequently developed. These networks have dealt with several topics, including: inclusion at the national level for the benefits of globalization to reach more people; local markets and policies; cross-border networks of production to promote decent work, growth and development; international migration as part of the Global Policy Agenda; international governance (including trade and finance); the relationship between culture and globalization; and values and goals in globalization. Gender and employment aspects were addressed throughout this work. The Reports on the Secretariat's Knowledge Network Meetings are available on the Commission's web site or as a special publication from the ILO (ISBN 92-2-115711-1).

During the course of these activities, a number of substantive background papers were prepared, which are now made available for wider circulation in the Policy Integration Department's Working Paper series (Nos. 16 to 38), as well as on the Commission's website.

Sean O' Siochru, of the Platform for Communications Rights, an umbrella group of NGO's concerned about the trends in media and communication, argues that the social consequences of the globalisation of the media sector itself are comparable to those of many other sectors and should be included as part of the overall issues surrounding globalisation. Yet the sector occupies a special place in processes of globalization and has a unique impact in two directions. The first is as an enabler of globalization. Media and communications industries are a leading sector in facilitating overall globalization. It is inconceivable that the pace and depth of globalization could have been sustained over the last decades in the absence of sophisticated telecommunications networking. Furthermore, content (or 'copyright') industries are at the forefront of cultural preparation for consumerism, essential for opening new markets and for breaking down cultural and other barriers. The second special characteristic of the globalization of this sector is as a powerful transformation agent of social, cultural and political structures. It is this set of, often unintended, side-effects of media globalization that have most impact of all. O'Siochru argues that the world currently finds itself at a media crossroad. At stake is the type of communication and media environment we seek to have, from local to global levels, for ourselves and future generations. He distinguishes and discusses two future directions. Major forces strongly propel one route, the commercialisation of media sectors and outputs, subsuming media and communication 'products' under general market rules. An alternative route, currently much weaker, would lead down the road of media and communications, focused on fulfilling human needs and reinforcing human rights, under a revised and invigorated structure of global governance.

\author{
Rolph van der Hoeven \\ Manager, Technical Secretariat \\ World Commission on the Social Dimension of Globalization
}

May 2004 


\title{
Social consequences of the globalization of the media and communication sector: Some strategic considerations
}

\author{
1. Media and communications in the \\ globalization process
}

\begin{abstract}
The electronic media and communication sector, which ranges from telecommunication networks and the Internet, through to radio, television and film, is itself among the most active in the current drive for the globalization of production, markets and trade. Although varying among the subsectors, its rate of expansion has been phenomenal, the centralization of ownership has been among the most marked, the transition from national public ownership to global private ownership is almost total and international trade (facilitated by the rebranding of telecommunication services as "tradable goods") has expanded apace. This has been accompanied by the reorganization of hardware, software and content production, and the global redistribution of activities.
\end{abstract}

The social consequences of the globalization of the sector itself are comparable to those of many other sectors, and include the restructuring of employment relations and conditions, and international competition for footloose capital based on cheaper labour. While these issues are very important in themselves, rather than being given special consideration on their own, they should be seen as part of the overall issues surrounding globalization.

Yet the sector, in its current trajectory, occupies a special place in processes of globalization that sets it apart from others. It has a unique impact in two directions. The first is as an enabler of globalization.

The media and communication industries are a leading sector in facilitating overall globalization. In the first place, the role of telecommunication is critical to globalized production strategies. It is inconceivable that the pace and depth of globalization could have been sustained over the past decades in the absence of sophisticated telecommunications networking. Furthermore, content (or "copyright") industries, such as television, music, video, film and the Internet, directly through advertising and indirectly through the promotion of consumerist and individualistic lifestyles, are at the forefront of cultural preparation for consumerism, an essential precondition and accompaniment to the opening up of new markets for a huge variety of products, and to the breaking down of cultural and other barriers.

Directly in their role as enablers of globalization, the social consequences of the media and communication sector are primarily mediated through the sectors that they facilitate. For instance, the social consequences of facilitating the emergence of globalized financial transactions and manufacturing industries are ultimately a function of the globalization of these sectors, while the social consequences of the opening of markets for "lifestyle" products, such as fast food and cosmetics, are a result of the growth of these sectors. But these impacts bring us beyond the main focus of this presentation. 
The second special characteristic of the globalization of the media and communication sector is as a powerful agent in the transformation of social, cultural and political structures. This is, of course, partly the flip side of media and communications as a means of opening new markets and softening up cultures for consumerism, although there is more to it than that. It is this set of (often unintended) side effects of the globalization of media that have the most impact of all, namely the evolving cumulative impact of the gradual commercialization of media and communications on critical social functions, such as the formation of individual and community identity, cultural and language diversity, the capacity to participate in the political process and the integrity of the public sphere, the availability of information and knowledge in the public domain, and the use of media for development, educational and human rights purposes.

These areas, the vital functions that media and communications must play in a society that respects democracy, human rights and economic, social and cultural needs, are the focus of this paper. The paper therefore highlights the major risks that are involved in the current process of the global commodification of media outputs and productions, and the commercialization of the dynamic that drives them. Priorities are also suggested for avoiding these risks in the context of international institutions and civil society.

\section{The following sections: ${ }^{1}$}

- outline the role of media in society, and why regulation has emerged everywhere;

- review a few of the main international bodies involved in regulating or governing media, with a brief glance at other actors on the global stage;

- describe some relevant trends in the governance of media and communications globally;

- describe two divergent avenues facing us, with an indication of where each might lead in the future; and

- conclude with a comment on the role of civil society and international institutions.

The central hypothesis is that we currently find ourselves at a media crossroads. At stake is the type of communication and media environment that we are seeking, from the local to the global levels, for ourselves and for future generations. Major forces are strongly propelling us down one route, the commercialization of media sectors and outputs, subsuming media and communication 'products' under general market rules. An alternative route, currently much weaker, would lead us down the road of media and communications focused on fulfilling human needs and reinforcing human rights under a revised and invigorated structure of global governance.

The crossroads metaphor is apt. If we travel down the former route, it becomes increasingly difficult to make our way back, as changes are locked into place, ratchet-like, by powerful institutions with an armoury of enforcement mechanisms and sanctions at their disposal. But building an impetus to move in the human rights direction will demand

\footnotetext{
${ }^{1}$ Many of these issues are dealt with in greater depth in Seán Ó Siochrú and Bruce Girard (2002), Global media governance: A beginner's guide, Rowman and Littlefield, Lanham, Boulder, New York and Oxford. This paper is based on Seán Ó Siochrú (2002), "Global institutions and the democratisation of media", in Pradip Thomas and Zaharom Nain (eds.), Revisiting media ownership: Global trends and local resistance, WACC and Southbound.
} 
a conscious and coordinated effort from advocates in international institutions and in civil society.

\section{Are media "products" just like other commodities?}

The existence of institutions to govern media presupposes a need to regulate media in ways that do not apply to other products of human labour. Yet the question is sometimes asked: Do we need to regulate media at all? Why not let the market decide what television, radio, newspapers and the rest can offer, just as it does for other goods, with governments and institutions intervening solely to ensure a level playing pitch? Why are media products so special that we cannot let media enterprises get on with what they claim to do best, namely producing what people want, measured by what they will pay for? If such an argument can be upheld at the national level, then it must surely apply, mutatis mutandis, at the international level.

Media products are different, not least because they are more than mere consumer goods: in important respects they also "produce" us. Mass media and electronic media in today's highly differentiated and compartmentalized world are becoming the primary means through which people interact with each other, beyond their immediate everyday contacts. Our sense of belonging, of being part of a wider community, a society, a culture, a nation, a single human race, is more and more "mediated through media". Beyond even an individual's relationship to society, the very mode in which society as a whole realizes its aspirations and fulfils its claims to offer freedom and democracy to its members, to support rational and fair legal, political and social institutions, indeed its legitimacy in claiming to act in the best interests of people in general, are all ideas and realities that are represented to us and brought to us primarily by the media. They provide us with the raw material, and often even the tools to comprehend our society beyond our immediate experience, and ultimately to participate in that society and perhaps even change it.

The notion of "media products" seems somehow too feeble to encompass the role that they play in our lives. In listening to, watching and reading media, we do not just consume, we interact. We interact with other people, and through them with society in general. We interact with ourselves, sometimes unconsciously, with our sense of sharing a common culture and of being a part of something beyond ourselves.

Virtually every society has therefore developed two distinct ways of governing media: firstly as a sector of economic activity, and secondly for their role in politics, society and culture. Each follows a separate rationale and is deployed in different configurations by different societies. The two approaches consist of:

- regulating the media as a sector of the economy, or industry regulation, similar to that of other economic sectors. In a market economy, this usually involves regulating in the interests of people as consumers by preventing market dominance, sustaining competition, ensuring a legally secure foundation, for instance for intellectual property rights (IPRs), and ensuring that public resources, such as radio spectrum, are allocated fairly; and

- regulating to sustain and strengthen the social, cultural and political role of media and communications or societal regulation. This is regulating in the interests of people as 
social, cultural and political actors, and includes the regulation of content and the policing of acceptable "outer limits" of specific content, based on social norms. This may involve everything from support for public service media to limits on advertising, expanding public domain information, universal service obligations and the censorship of content.

Forms of regulation often come into conflict. Too strong an emphasis on regulation as an industry in a market economy may be at the expense of the media's social or cultural roles. For instance, intellectual property rights by their nature involve a trade-off between the monopoly economic rights of content owners and public domain information available freely to all.

From a human rights perspective, societal regulation should have clear preference over industry regulation in areas of conflict, but also in terms of determining overall priorities. Within industry regulation, where they conflict, but also in general, the rights of consumers should be preferred over the interests of industry. Unfortunately, as we shall see, precisely the inverse holds in the current situation and trends. Powerful countries, with a view to global dominance, promote corporate needs over those of people as consumers of media; and societal regulation, along with people's social, cultural and political needs in relation to media and communications, are shoved to the bottom or ignored altogether.

As the media globalize, questions of regulation are posed at the international level. As the national boundaries of media are gradually relaxed, the international level emerges. Media and communications issues have therefore developed their own international institutions, or have become integrated into the activities of existing general purpose institutions.

\section{Global governance institutions and actors in media and communications}

Four of the main international organizations involved in regulating and governing the media at the global level are covered below. There are others, but the International Telecommunication Union (ITU), the United Nations Educational, Scientific and Cultural Organization (UNESCO), the Internet Corporation for Assigned Names and Numbers (ICANN) and the World Trade Organization (WTO) stand out. In brief, each has the following responsibilities and powers.

\section{Media governance institutions}

The International Telecommunication Union (ITU), founded in 1865 and the oldest of the four institutions, is responsible for the allocation of radio spectrum across borders, terrestrially and via satellite, for the purposes, among others, of telephony (mobile and fixed), data, television and radio. The use of spectrum is coordinated to prevent interference and border "spillover", and slices of it are allocated to different uses and users. Since it is a scarce public resource, its allocation among users is an important and contentious issue at the international level. The ITU also divides out the satellite orbital slots, including the valuable and scarce geo-stationary orbit. 
A second major function of the ITU is in standardization for telecommunication networks. The standardization of equipment and protocols can also be highly contentious, as it is tied up with issues such as market control. A further activity has been to facilitate the so-called "accounting rate" system, whereby telecommunication operators reimburse each other for the use of their networks for the completion of calls in another country. In net terms, many poorer countries have, for a number of reasons, benefited from these cross payments, which sometimes yield significant amounts of foreign exchange. The ITU is also concerned with extending telecommunication to less industrialized countries, but has only very limited means by which to do so.

The ITU therefore has responsibility for several narrow but critical areas of strong interest to governments, corporations and civil society alike.

The United Nations Educational, Scientific and Cultural Organization (UNESCO), on the other hand, has much "softer" responsibilities. But these extend to many areas of social concern. UNESCO is important less for its formal powers and its capacity to enforce multilateral agreements, than as a forum for voluntary cooperation on (usually noncontentious but necessary) issues of mutual concern across a wide area, and for raising and debating issues of global import. UNESCO in its early decades was instrumental in many conventions, declarations and congresses, overseeing agreements on issues such as the exchange of audio-visual content for educational use, cross-border direct satellite broadcasting and copyright exemptions for development purposes. In the late 1970s to the mid-1980s, it came to the fore as a debating arena for global communication issues in the context of the New World Information and Communication Order (NWICO). ${ }^{2}$ However, its fingers were badly burned, as Cold War politics and the entrenched positions of some of the major powers eventually led to the defeat of voices calling for more open and democratic global media flows and structures. UNESCO has never fully recovered in terms of facilitating vibrant debate, and indeed the United States has still not rejoined it after leaving in the mid-1980s believing, probably correctly, that it can wield more influence by remaining outside.

In 1995, the UNESCO-sponsored World Commission on Culture and Development put forward some significant proposals regarding media, raising the idea of a tax on the use of spectrum, with the proceeds to be utilized for non-commercial programming for international distribution, and questioning the growing concentration of media ownership. However, it is probably indicative of UNESCO's broader constraints that these failed to be ratified, or even discussed, at the follow-up intergovernmental meeting in 1998. Nevertheless, UNESCO continues to support progressive media initiatives and to sponsor debate at a lower level.

The newcomer is the Internet Corporation for Assigned Names and Numbers (ICANN). ${ }^{3}$ Established in 1998, its main function is to manage the process of assigning names and

\footnotetext{
${ }^{2}$ There are many publications on this subject. For a recent retrospective review see: Richard C. Vincent, Kaarle Nordenstreng and Michael Traber (eds.) (1999), Towards equity in global communication: MacBride Report update, Cresskill, Hampton.

${ }^{3}$ ICANN is not alone in being dedicated to governing the Internet. The Internet Architecture Board (IAB) oversees technical development, and is composed of both the Internet Society (ISOC), a body of coordinating professionals, and the Internet Engineering Task Force (IETF), the accredited standards body. The World Intellectual Property Organization (WIPO), by agreement with ICANN, is a key body in resolving domain name disputes.
} 
numbers for the Internet, an issue that has gradually taken on huge commercial and legal significance. ICANN initially saw itself as primarily technical, but its management of IP addresses and of the Domain Name System (DNS), which ultimately controls the routing of Internet traffic, quickly moved into economic, political, social and even cultural domains.

ICANN is interesting not just for what it does, but for how it does it. It is constituted as a non-profit private-sector corporation under Californian law, with a view to allowing the United States Department of Commerce to maintain ultimate control over the DNS (which it still does). This places it in the non-governmental sector. Its governance is still in transition, and has not as yet attained stability, although the at-large membership (Internet users who registered for the process) did have the opportunity to elect five of the 19 directors, the rest coming from the initial board and nominated by associated organizations. Its fragility has been underlined recently, with a decision by the ICANN board to back-pedal on civil society participation, and the robustness of the basic structures has been called into doubt. Nevertheless, it does point to the feasibility of different approaches.

Last and certainly not least is the World Trade Organization (WTO), which straddles some key areas of media and communications and is set to extend its mandate further.

Although WIPO is a United Nations agency set up to oversee intellectual property rights (IPRs), the WTO (which is not a United Nations organization) gained decisive preeminence with the signing of the TRIPS agreement in 1995. The WTO now has at its disposal some of the strongest policing and enforcement powers ever ceded by governments to an intergovernmental body, and it uses them extensively in the field of copyright. The copyright industries, such as film, music, books, television and magazines, include the world's largest media corporations, and the WTO underwrites and enforces their rights in all the TRIPS signatory countries. The WTO is also the forum in which these rights have become, on the one hand, narrower, retaining only the model used by wealthy countries, and on the other, deeper in terms of duration and breadth.

In telecommunications, since the shift from monopoly national providers to competitive international supplies, the trade paradigm of the WTO has also come to the fore. An area of interest here is universal services policies, under which governments can require cross-subsidization from large business users and urban areas to domestic and small users and rural areas. The WTO Agreement permits this only where they do not interfere unduly with competition - a vague formulation that is yet to be tested. The move to privatized trade in telecommunications is also leading to the redundancy of the ITU's accounting rate system and to the net loss of foreign earnings for some of the poorest countries.

Finally, the WTO is active in the field of media products. In the area of magazines, newspapers and other non audio-visual media, countries are not allowed, on pain of strong financial or trading sanctions, to introduce barriers to market entry on the basis of the protection of cultural integrity. An attempt was made in the Uruguay Round to lay down the same rules for film, video, television and audio-visual products, which failed due to European and other opposition. But it will be back on the table at the Doha Round of negotiations.

These are some of the individual institutional players. They are not, however, a power unto themselves. 


\section{Other actors}

Intergovernmental organizations (ICANN being an odd one out) are ultimately subject to control by governments. In formal terms, they exercise no more power than is (more or less voluntarily) ceded to them by governments. Not that all governments are equal - a range of pressures can be brought to bear by powerful governments to force others to cede their authority to a treaty or agency. The WTO, for instance, is regularly accused of being the arena for such strong-arm tactics. But governments in general remain the most powerful single set of actors.

Nevertheless, when intergovernmental agreements are reached and ratified, they exhibit a tendency to take on a life of their own, and the central role of the administering agency in interpretation and implementation lands it in the driving seat. Accordingly, the agencies are gradually carving out a sphere of influence and must thus be considered as actors in their own right.

The global private sector, through multinational corporations and their well-funded associations and lobbying bodies, is also a major force on the international scene. Its avenues of influence extend everywhere, through some major governments, which virtually identify the national interest with that of their corporations, by sitting on the arbitration boards of the WTO, recruiting their former senior officials and the concerted long-term lobbying of international agencies. However, in media and communications, as in other areas, the private sector does not always speak with one voice. For example, the issue of copyright over pages downloaded from the Web pitted the "copyright" industries against the Internet and telecommunications industry, with the former seeking to extend copyright to even temporarily downloaded pages. The latter won out at the end of the day, and the Web for the moment retains that aspect of public access.

Nor does the private sector always get its own way. Non-commercial non-governmental organizations (NGOs) have enjoyed special access to the United Nations system since its foundation (oddly, the ITU is an exception, and the WTO, which is not a part of the United Nations system, also closes out NGOs from any formal role). The role of NGOs has gradually expanded and taken on concrete forms in terms, for instance, of access to information and influencing agendas. However, it is outside institutions, for example through mobilization at major events, that civil society organizations are currently flexing their muscles and staking a claim to be heard. In relation to media and communications, civil society has so far as a whole been largely, and surprisingly, silent, viewing the media primarily as tools to promote their agendas, rather than as active and hugely influential agents in their own right. But this may be changing. 


\section{Influences and trends in governance}

Media trends, and how to influence them, must be set in the wider context.

Dominating this context is the new phase of globalization which is characterized, on the one hand, by a diminishing role in certain respects for the nation State, coupled with the limited and declining capacity of most United Nations multilateral agencies to cope with expanded global governance tasks. Into the vacuum, deliberately engineered by powerful nations, are stepping liberalized industries across commodity, service, information and communication technology sectors, with their own integral and exclusive forms of "governance" and control, overseen by their favoured international institutions, including the WTO, G8 and OECD. The risk for United Nations agencies is that they will flounder in the wake of these unelected elites.

A simplified global institutional dynamic can be identified. United Nations multilateral agencies, with at least some claim to upholding balanced global development, are struggling against a trade and commercial paradigm based on private property and contractual rights driven largely by non-United Nations organizations, especially the WTO, and supported by the more powerful governments and the interests of private capital. Although they are unable to act in concert, the majority of world governments are probably on the side of more balanced development, as are most United Nations agencies themselves, in accordance with their remit and secretariats, and civil society.

But the media industry is not only a lead sector in the rise of the trade paradigm. It provides many of the tools and instruments that drive it along. The media, and especially cultural content industries, help prise open new international markets through advertising and the promotion of the consumerist lifestyles in which entertainment is usually packaged. The pace of globalization would be almost inconceivable without telecommunications and information and communication technologies (ICTs) in general. It is because the media occupy this key double role that attempts to influence their course of development will always confront the larger forces of globalization.

As micro-expressions of these macro-trends, a number of distinct intertwining strands are likely to influence the future media landscape.

The first of these strands is the declining role of most governments and United Nations organizations in the governance of media and communications, and the ascendance of the trade paradigm. In this respect, five points have stood out over the past decade or two:

- the transfer to the WTO of sovereign government power in the area of telecommunication and intellectual property rights (IPRs), and possibly in the future regarding audio-visual products and the capacity to protect cultural diversity and identity;

- the loss of IPRs by WIPO to the WTO and the consequent strengthening of trade and competition rules over human rights, cultural and social considerations;

- the general decline of the ITU as the global governing body in telecommunication, with much of its previous domain moving over to trade and market mechanisms;

- the inability of the multilateral organizations to agree on the regulation of foreign direct satellite broadcasting, and the consequent absence of regulation in the sector; 
- the careful distancing of UNESCO from political issues and any debates casting doubt on the supremacy of the trade and market paradigm; and

- the failure of the United Nations system to gain governance over the Internet, underlined by the creation of ICANN as a non-governmental and non-representative body receiving its power directly from the United States Government.

Many of the above are actively pursued by governments, belying any simple argument concerning the eclipse of the nation State by some competing power. The loss of sovereignty to global market forces is seen by many at the individual level as being to their commercial benefit. Both the European Union and the United States, for instance, anticipated and achieved huge benefits from the opening of telecommunication markets in less developed countries (for which the long-term benefits are a lot less clear). However, the net effect is the loss of the sovereign power of governments and its transfer to selected multilateral organizations, and most significantly the WTO.

The second strand is the related emergence of closed quasi-governance organizations controlled by the private sector, pushing market mechanisms to the fore in media and communications.

As noted above, the private sector is already a major player, perhaps the most powerful, in the global arena. Yet it falls short of what it needs to achieve its ultimate ambition: freedom to operate when, where and how it wishes in an unrestricted global marketplace for all media and communications products. The constraints faced by the private sector in this respect include: the exclusion of the audio-visual sector from the WTO Uruguay Round agreement (ironically because of differences between the United States and the European Union); market barriers based on cultural preservation; the inability to buy and sell satellite slots and radio spectrum at will; continuing government ownership of some telecommunications networks and media, as well as universal service obligations; time-consuming negotiations in United Nations agencies; and public interest regulation at the national level. These and other nuisances cramp the style of private sector operators and cost them profits. Supportive governments began to reinforce existing closed semisecretive clubs, such as the G8, OECD and the World Economic Forum (Davos), and invited the private sector in as participants. The concepts of the Global Information Infrastructure and the European Union's Global Information Society were refined here, in close consultation with business and landing them firmly in the driving seat. Civil society and development issues travel in baggage class, offered amid much publicity some pilot projects and fine-sounding but ultimately self-serving plans for bridging the "digital divide". Latterly, entirely new entities have been coming into being to represent business and patron governments, such as the Global Business Dialogue on Electronic Commerce and the Global Information Infrastructure Commission, the core objectives of which are to plot a future for governance in which business interests are permanently to the fore.

Nevertheless, the trend towards private sector governance faces an ongoing legitimacy deficit. Credible and durable governance structures are not yet in sight.

A third strand affecting the future of media and communications is the tentative emergence of the influence of civil society and the rise of "people's media".

Although civil society, in the form of NGOs, has long been recognized within the United Nations system, it was only at the Earth Summit in 1991 that it began to take on a more organized and collective role, moving on from individual consultations with ECOSOC and 
the specialized agencies. But it was because of NGO activity outside the United Nations system, at least formally, that the other players began to sit up and take notice. The success achieved in opposing the Multilateral Agreement on Investment (MAI) initiative and the street demonstrations against the WTO, G8 and others, converted civil society into a new category of actor on the global scene, the implications of which are still being played out. In media and communications, however, there has been little direct action, and only slightly more in formal intergovernmental structures. The organization of civil society around media and communications can be seen in terms of three trends:

- One of these is the emergence of international advocacy and activist groups in media and communications concerned with global trends and pushing for enhanced democracy and the right to communicate. These include the People's Communication Charter, the Platform for Communication Rights, the World Association of Community Radio Broadcasters (AMARC), the World Association for Christian Communication (WACC), the Communication Rights in the Information Society (CRIS) campaign, the Association for Progressive Communications (APC) and many others. ${ }^{4}$

- Another trend is the more frequent inclusion of a right to communicate and similar calls in the statements and goals of (non-media) umbrella NGO and civil society entities and events, such as the World Civil Society Conference (Montreal, December 1999) and the World Social Forum in Porto Alegre in January 2001 and 2002. ${ }^{5}$ This suggests that the issue is slowly but steadily gaining a profile across civil society as a whole.

- A third trend is the growth of community or "people's media" in many countries across the world, motivated in large part by the need to provide an alterative to mainstream media and to democratize media structures and access. ${ }^{6}$ These include public access and community access television, community and independent non-profit radio (many under the umbrella of AMARC), the global community networking movement, Indymedia Centres, as well as regional and global information services, such as MediaChannel, WETV, FreeSpeech TV and others, which not only offer alternative media content, but also comment extensively on the media. There is also some evidence that these issues and actions are beginning to emerge in less industrialized countries, which suffer the brunt of some of the worst excesses of media globalization. This augurs well for the future. ${ }^{7}$

The potential impact of NGOs on global governance structures has yet to be tested. But the World Summit on the Information Society (WSIS), held in December 2003 and led by the ITU, provided an opportunity to do just that. Several groups are already organizing to broaden the WSIS agenda to deal fully with issues of information and media and to enable it to play a catalytic role in civil society organization in media and communications. ${ }^{8}$ However, an enhanced role for civil society in the global governance of media would also raise issues of legitimacy and representation, just as it does in all other sectors.

4 See, for instance: www.amarc.org, www.comunica.org, www.wacc.org.uk, www.penelopes.org, www.apc.org, www.crisinfo.org

5 See www.forumsocialmundial.org.br/ for the outcomes of the World Social Forum held in 2002.

6 See $\underline{w w w . d e v m e d i a . o r g}$ for a composite list.

7 Community radio, in particular, is gaining momentum in countries such as Nepal, Mali and much of Latin America and the Caribbean.

8 See www.itu.int/wsis/ and www.geneva2003.org for official sites and, for instance, www.comunica.org for the civil society response. 
A fourth strand that is likely to influence the future of the media landscape is the growing sophistication of the less industrialized countries in relation to their role in multilateral organizations. Over the years, the less industrialized countries have expressed concern at the imposition of external media content and structures and the liberalization of the telecommunications and other communication sectors. Although their motivations vary, many have drawn on genuine concerns and an informed understanding of the long-term risks. The debates in and around UNESCO during the 1980s, with the non-aligned movements playing a central role, for the first time raised a great variety of issues in global debate concerning such matters as media, the press, information and data flows, and the concentration of ownership. ${ }^{9}$ The virulent opposition of the United States and the United Kingdom, which in part caused their departure from UNESCO, is an indication of the extent to which these regimes felt their interests threatened.

Recent decades have been more muted. The issues have not gone away, but have been eclipsed by more immediate and pressing needs. Media and communications issues have often been put in the basket of areas that were, regretfully, to be traded off in the WTO, often with very little return. However, some of the larger countries, such as Brazil and India, have their own media sectors and have attempted to negotiate with a view to carving out a niche for their own industries within the overall neo-liberal paradigm.

Nevertheless, there is evidence of the emergence in some countries of a more sophisticated long-term strategic understanding of the role that media and communications can play, not just in economic terms, but also socially, politically and culturally. Reference may be made in this respect to: South African President Nelson Mandela's refusal to simply accept what was offered at the G7 Summit on the Information Society and Development in South Africa in 1996; the success of a group of West African countries in brokering a deal that kept copyright away from material downloaded from the Web; ${ }^{10}$ and the more recent positions and actions of President Konaré of Mali in supporting radio and other media. These suggest a growing willingness to cooperate between less industrialized countries, but also with more progressive industrialized countries, which has been absent for some time.

\section{Two scenarios for the future of the media}

A somewhat circuitous route has been trodden in our exploration of global institutions and the democratization of the media. Having positioned ourselves at a crossroads of the future of media and communications, we then posed the question of why media need regulation and governance at all, and hence why institutions have sprung up nationally and globally to regulate them. The answer was followed by a description of the main governance institutions and what they do. A dynamic was introduced, in the form of some trends in media and communications that are likely to influence these institutions.

9 See the MacBride Commission Report: Many voices, one world: Report by the International Commission for the Study of Communication Problems, UNESCO, 1980.

10 A proposal from a group of African countries enabled the software and telecommunication industries to defeat the efforts of the United States, European Union governments and the "copyright" industries at a WIPO conference in 1996 to extend copyright to temporarily downloaded Web pages. This ad hoc coalition of advanced industry and African countries would yield benefits to the latter only in the long-term. See Siochrú and Girard, op. cit. 
We now find ourselves back at the crossroads. Two avenues are presented below, down which we may move, each leading to a very different scenario. They are at opposite ends of the spectrum, but well within the bounds of possibility. Scenario 1 is based on the extrapolation of the commercially driven scenario to its ultimate, but still plausible, conclusion. Scenario 2 sees the democratic core of the current system revived and extended.

\section{Scenario 1: \\ A dominant trade and liberalization paradigm}

The first scenario envisages current dominant trends proceeding several steps further forward. The main thrust is for the commercial and liberalization logic to permeate virtually the entire media and communications sphere, nationally and internationally, largely at the expense of their social, cultural and political dimensions. Multinational industry reigns, and the United Nations system is gradually displaced by an ever more powerful WTO, closed intergovernmental clubs of powerful governments and private sector allies. This leads to a contraction of the public sphere and of human rights imperatives, and an extension of the private sphere and the economic rights of those that can afford to exercise them.

At the macro level, this would require the resolution of current struggles concerning, for instance, the WTO and the Bretton Woods institutions, in favour of the neo-liberal approach, with little structural change and the emerging governance needs settled in compliance with the market driven status quo.

For the media and communication sector, the structural conditions and regulation of this scenario would include:

- unimpeded global trade in media and cultural products, with no protection on the basis of cultural, social or environmental outcomes;

- a fully enforceable and all-embracing intellectual property regime that principally benefits owners;

- the virtual elimination of universal service instruments in telecommunication, deemed to interfere with competition and the operation of the market;

- heightened commercialization and looser regulation of radio, television and other mass media, and the obligation for public service media to compete in the marketplace;

- the commercialization of spectrum terrestrially and in space, to be sold to the highest bidder; and

- the gradual extension of industry self-regulation in emerging media subsectors.

Were these trends to gain an inexorable momentum, other global stakeholders would face stark choices. The United Nations system would be forced to choose between accommodating the new world order or risking redundancy, being cash-strapped and lacking the internal capacity to devise and enforce an alternative development or human rights based agenda. 
Less developed countries, similarly, would probably divide between a minority which object, and are therefore sidelined from the globalization process, or perhaps suffer the full rigour of what they have already signed up to, and a majority that believe they have no option but to join in.

Civil society, realizing the dangers too late to mount effective opposition, would find itself more or less excluded from this domain altogether, reduced to a spectator as the global media circus rolls on.

The medium-term outcomes of such a scenario might be as follows:

- the number of media channels and sources available grows, especially from international sources by direct satellite broadcast and other means;

- within these, the diversity of programme content diminishes and quality falls;

- public service media disappear or dwindle to niche providers;

- media ownership and content portfolios are further concentrated and centralized;

- support measures for local, community and people's media disappear in the clamour for market sustainability;

- the public domain shrinks, as lucrative parts are hived off to profit-making concerns; and

- infrastructure and new services in telecommunications grow, but are confined mainly to urban and business markets, leading to greater disparities.

Brought to its (unlikely) ultimate conclusion, within a few decades media and communications could be expunged of all voices of dissent and criticism, an entire generation having grown up knowing little else, not just incapable of autonomous political action, but unaware of the concept and practice; the gap between those with access to media and those without accentuating the already great economic inequalities; and media content and information becoming the almost exclusive property of giant corporations controlling creativity and diversity on the short rein of profit maximization. Most insidiously, the process slowly but surely transforms the very wellspring of ideas and creative capacities, ultimately yielding a self-perpetuating cycle that stifles genuine diversity and is purged of all dissent and non-conformity.

The circle is complete. The end point feeds back to the beginning. A consistent and coherent pattern of domination impels media in a downward spiral to a new Information Age Dark Era.

Is this the brave new world we are irreversibly careering towards? Probably not, at least not the whole way.

The core weakness of this scenario is the legitimacy deficit that it would generate. Current tensions would intensify and the systematic roll out of this agenda through all media would require such an ever-growing abuse of power that it probably could not be sustained for long. The virtually complete subjugation of the public interest to commercial capital, although possible in individual countries and indeed approximated already in the United States, would encounter sustained and deep resentment and opposition globally. Many 
governments, both powerful and less so, would baulk at the prospects of such explicitly one-sided development and its long-term implications.

A more credible future for this scenario would therefore require the co-option of major civil society interests and of some governments of less industrialized countries. This would in turn mean a series of concessions in non-core areas that would at least mitigate the outcomes. Nevertheless, finding ourselves even half way down this route should be enough to frighten most ordinary people.

\section{Scenario 2: Multilateral cooperation reborn}

The second scenario represents a decisive shift in the other direction, reinvigorating the democratic core of the media and communications governance structures. A reformed and rejuvenated United Nations system, with mechanisms enabling the participation of civil society, as well as governments, regains the upper hand in media and communications governance. It instates social, economic and cultural rights and the satisfaction of human needs as the core objective, and economic and political structures as the means for their delivery. Social and cultural needs and equitable economic relations are elevated as objectives above the pursuit of any particular economic model.

This scenario would bring some significant regulatory and governance changes:

- a review of the rules of international trade in media products, with priority accorded to cultural renewal and potential social risks, and a range of measures for citizens and governments to influence the impact of external media products, including advertising;

- the promotion of a range of measures for the provision of universal access to telecommunication and media, in rural and remote areas and amongst marginalized groups, even where this significantly impinges on the operation of market mechanisms;

- $\quad$ support for global public service and development-oriented media, perhaps through a multilateral agency, including ongoing funding from a tax on commercial satellite use, on the turnover of the media industries generally or another similar source;

- enforceable mechanisms to halt, and indeed reverse the concentration of media ownership;

- an international agreement on media transmitted across borders that covers issues relating to content quality, diversity and independence, and to freedom from political and other interference;

- the reformulation of intellectual property rights to ensure wider and quicker access to the public domain and to support development goals, while preserving incentives for creativity and innovation in media content; and

- the allocation of international spectrum, as a global public good, explicitly factoring in the social, cultural and development needs of marginalized countries and groups, as well as public service and people's media, and dedicated spectrum at no or reduced cost.

Faced with such a panoply of checks and regulations, in this scenario the transnational corporate sector would find itself forced to roll back expectations and operate 
internationally for the first time within a regulated environment. Some global corporations might be obliged to split up. Profitability would probably suffer a temporary setback until the sector is reorganized in line with the new rules of the game. Civil society, at least some of the less industrialized countries and marginalized groups in general would see an expansion of media and communications opportunities, by being offered access of which they could hitherto only dream in terms of both participating in media and promoting their diverse views, cultures and ideas.

Medium-term outcomes might include the following:

- a significant rise in non-commercial media, with a mission specifically to contribute to a media environment that puts people at the centre, from the local to the global levels;

- the emergence of well-funded quality public service media globally, and perhaps regionally, alongside the commercial sector;

- a reduction of advertising presence and impact and of the need to maximize advertising revenues, resulting in the alleviation of commercial and consumerist pressures;

- the emergence of public communication spaces for informed democratic dialogue on issues of global concern, and perhaps of a global civil society;

- more equitable access to media services, including telecommunication, reducing the gap between wealthy and poor regions and groups.

Such a scenario could conceivably become a realistic prospect, for instance if it were to be supported by a number of governments of breakaway industrialized countries, collaborating with a majority of less industrialized countries and riding on the back of a wave of civil society lobbying and action at the national and international levels.

Realistically, any shift at all in this direction would be (and is currently) opposed forcefully by the United States and some other powerful countries, and by most of the institutions through which these countries cooperate, such as the G8, OECD and WTO. A break in these ranks would be an essential prerequisite. The private sector would use all possible means to oppose such trends. Global media owners have not in the past stopped short of explicitly deploying their media to protect and expand their private interests, and the threat in this case is probably strong enough to provoke an extreme reaction.

Such a radical shift would confront other problems. There are genuine concerns regarding the capacity of current multilateral governance structures to function democratically and effectively. Such a scenario would very quickly face its own crisis of legitimacy, given the generally unaccountable and relatively opaque nature of the United Nations system, with its composition that is almost exclusively confined to governments. To be plausible and gain the level of support that would be required, a reconstructed United Nations system would need greater accountability and transparency and, most important, extended participation beyond governments to embrace other actors, especially civil society and the private sector.

Yet the full realization of Scenario 2, in the absence of a broader move to rethink global governance structures and refocus them on human development, stretches credulity somewhat. A fully fledged Scenario 2 would require entirely new instruments, even agencies in the sphere of media and communications, setting the United Nations system on a par with, or indeed above the WTO in its capacity to enforce agreements; and 
counterbalancing the WTO trade focus with explicit consideration of social and cultural rights and other economic and sustainability objectives. This is likely only against the backdrop of a much wider movement to reinvent global governance. And a very broad, powerful and robust coalition indeed would be required to wage a sustained campaign to see this agenda through. It would undoubtedly have to incorporate elements of civil society globally, especially in the industrialized countries, and would require concerted action from many governments and courageous stances from the United Nations system. 


\section{Conclusion}

At the risk of mechanical oversimplification, the power dynamics between the main global actors are sketched out below as they apply both generally and to media and communications:

Figure 1: Current power distribution of global actors in media governance

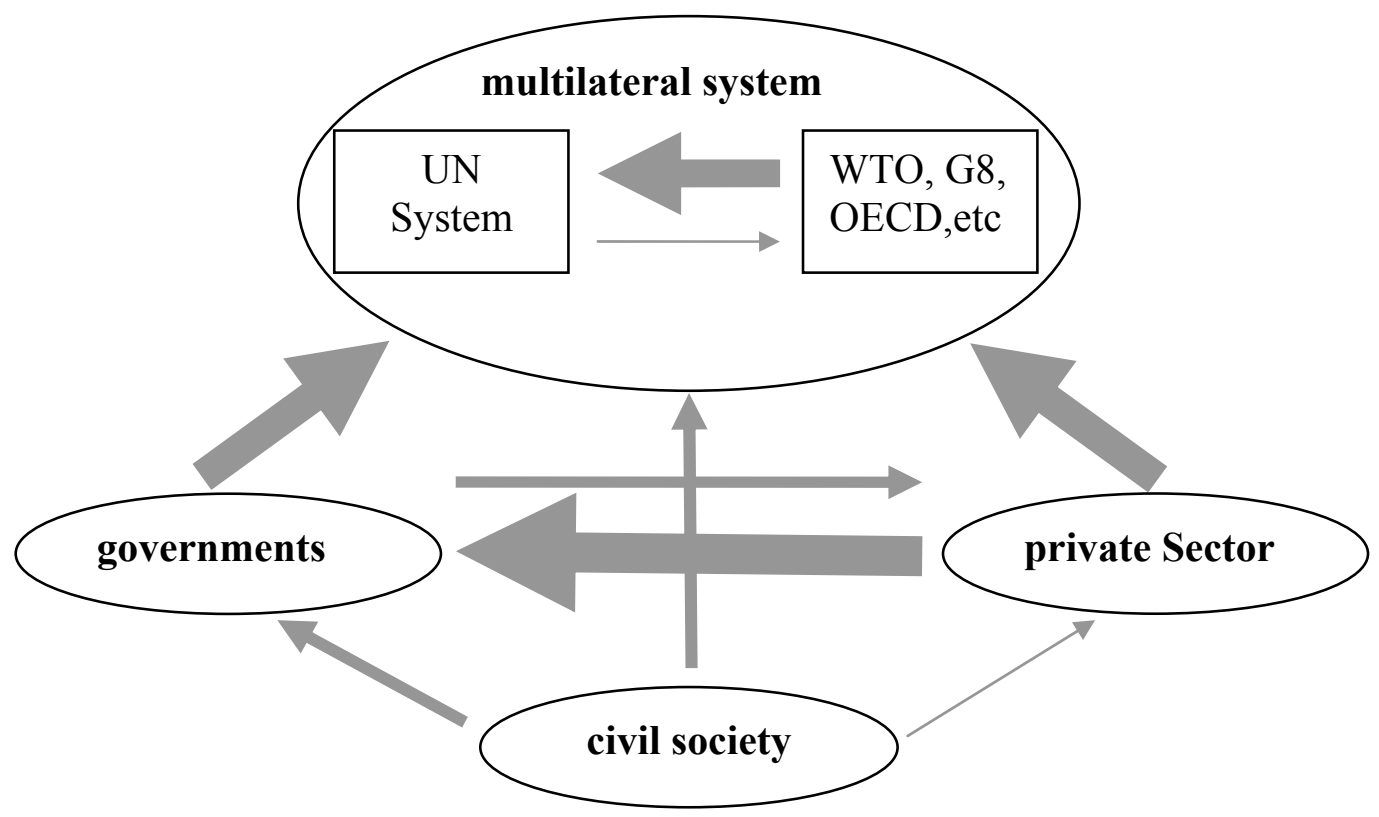

At present, the balance of power lies clearly with the private sector. Its direct influence on global governance is enormous, both through lobbying and directly through non-United Nations entities. But its real grip on power is secured through powerful governments which identify their own interests with those of the private sector. Yet, even these governments have individually relinquished much of their direct control over global corporations, having pooled it in multilateral agencies over which they hope that they can maintain secure control.

In the multilateral sphere, the United Nations system is losing out to the WTO and other informal organizations controlled by wealthy countries, both in terms of formal powers and in guiding strategic directions.

Civil society has long had some limited influence on governments and has recently flexed its muscles in relation to the multilateral system. But it would be a mistake to overestimate its current strength and power base, especially in media and communications.

Despite an apparent loss of sovereignty, governments still play a pivotal role. Even with much sovereignty pooled, they maintain formal control in most areas of governance. At the end of the day, what governments cede individually they can take back collectively, or at least they can influence those benefiting from what has been ceded. 
Of course, this diagram fails to differentiate between governments, and particularly between wealthy and poorer governments. But no matter. The intent is to focus on the role of civil society and the need to work at several levels at once.

A more balanced distribution of power from the perspective of civil society and human rights, indicative of a move towards the second scenario, is represented below:

Figure 2: A more balanced power distribution of global actors in media governance

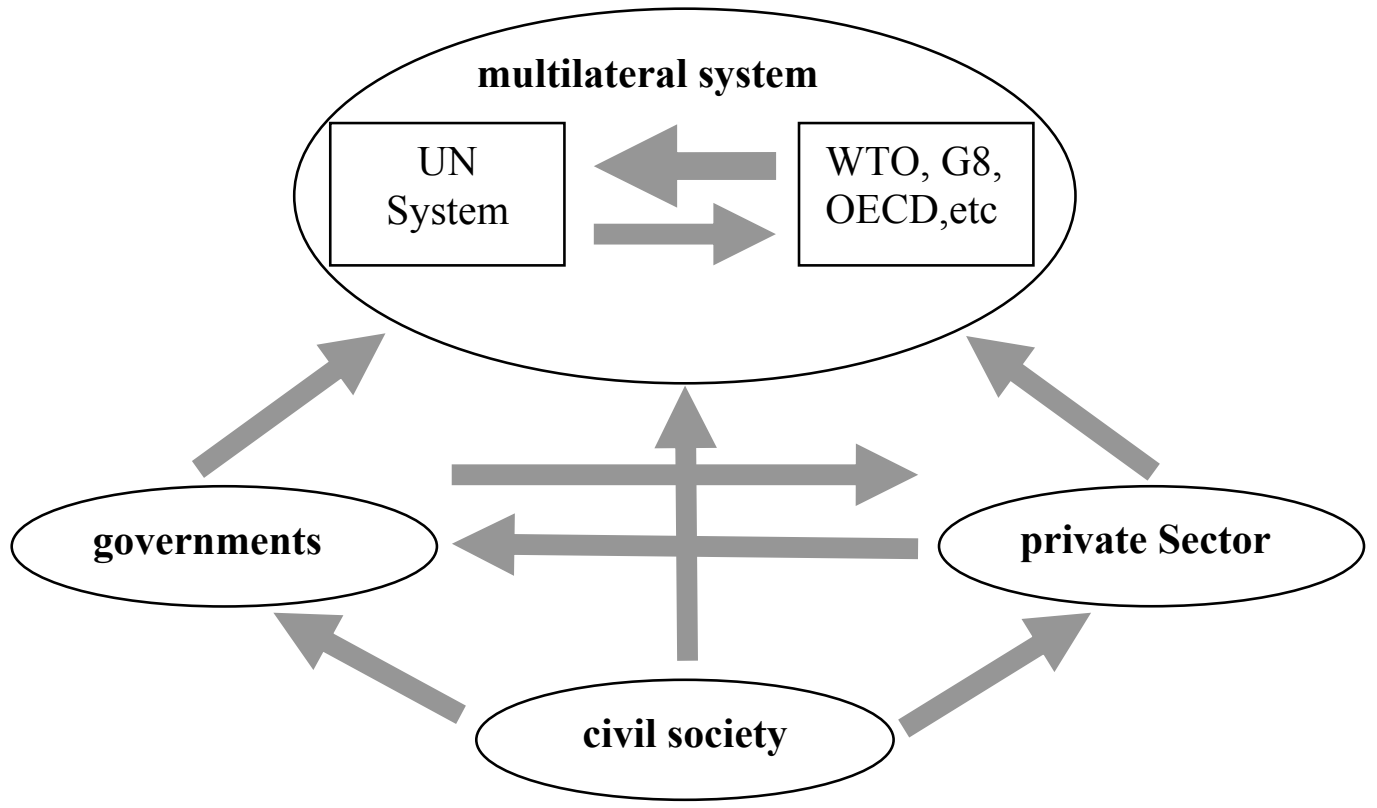

From a strategic civil society point of view, this would mean acting in several ways at once.

First, sustained pressure would have to be brought on multilateral agencies, acting both within and outside formal structures. The "surprise" factors of recent years are likely to be replaced in time, or supplemented by a "long march through the institutions", based on influencing and lobbying at every step. Yet this can have little permanent impact if governments cannot also be persuaded to focus more on human rights and the needs of civil society, and to begin to make a collective stand against private interests. National lobbying and interaction will therefore be vital. At the same time, the private sector can also, although ultimately only to a limited extent, be influenced directly through consumer and shareholder action and by building up a "civil society" enterprise sector of cooperatives, fair-trade companies and the like.

Ultimately, this means coordinated civil society organization at these levels, with coordination and concertation in terms of themes and timing being vital if action is to be effective. It will also be critical to establish constructive and effective cooperation between civil society and United Nations agencies, so that they can work together to raise the human rights agenda and mutually reinforce the impact of their respective actions.

The schema above is generic enough to be applicable both to achieving global human rights as a whole and to the area of media and communications. Indeed, for better or for 
worse, significant change is unlikely to come about in the governance of media and communications except in the context of an overall reappraisal of governance structures. Yet, just as media and communications are at the forefront of recent and current tends towards the market-driven consumerist model of society, so, if turned around, they could form the spearhead of a new human rights based model. Taking over the media and creating their own media is often among the first actions of national revolutionaries and the authors of coups d'état alike. So too, at the global level, human rights activists could do worse than to concentrate their early efforts on creating new media for a new world, and progressive international institutions could focus on building a global media regulatory framework that puts the needs of peoples first. 


\section{Policy Integration Department Working Papers prepared for the World Commission on the Social Dimension of Globalization}

No. 16 International finance: Meeting the needs of people in developing countries, José Guilherme Almeida dos Reis

No. 17 The gender dimensions of globalisation of production, Stephanie Barrientos, Naila Kabeer and Naomi Hossain

No. 18 Social exclusion in the context of globalization, Jan Breman

No. 19 Gender and globalization: A macroeconomic perspective, Çağatay Nilüfer and Ertük Korkurt

No. 20 Globalization, social exclusion, and work: With special reference to informal employment and gender, Marilyn Carr and Martha Chen

No. 21 Resources for social development, Antony Clunies Ross

No. 22 Does the new international trade regime leave room for industrialization policies in the middle-income countries?, Alisa DiCaprio and Alice Amsden

No. 23 Social dimension of globalisation in Latin America: Lessons from Bolivia and Chile, Alvaro García Hurtado

No. 24 Globalization: Social impact and policy actions: A partly annotated bibliography, Bernhard Gunter and Rolph van der Hoeven

No. 25 The social dimension of global production systems, Susan Hayter

No. 26 Reforming global economic and social governance:

a critical review of recent programmatic thinking, Jeremy Heimans

No. 27 Corporate social responsibility: An issues paper, Michael Hopkins

No. 28 Upgrading in global value chains, John Humphrey

No. 29 Implications of globalization and economic restructuring for skills development in Sub-Sahara Africa, Richard K. Johanson

No. 30 The outcome and impact of the main international commissions on development issues, Frédéric Lapeyre

No. 31 Globalization and structural adjustment as a development tool, Frédéric Lapeyre

No. 32 Globalization and perceptions of social inequality, Malte Luebker

No. 33 The changing structure of trade linked to global production systems: what are the policy implications?, William Milberg

No. 34 Corporate social responsibility: An overview of principles and practice, Jill Murray

No. 35 Inclusive development strategy in an era of globalization, Ignacy Sachs

No. 36 Social consequences of the globalization of the media and communications sector: Some strategic considerations, Seán Ó. Siochrú

No. 37 Globalization, history and international migration - A view from Latin America, Andrés Solimano

No. 38 Towards a different kind of globalization, or how the anti-globalizers view the world, Gijsbert van Liemt 